\title{
A note from Stephen $P$. Jenkins, incoming editor-in-chief
}

\author{
Stephen P. Jenkins
}

Published online: 19 March 2014

(C) Springer Science+Business Media New York 2014

It is an honour and privilege to become the editor-in-chief of the Journal of Economic Inequality (with effect from 1 February 2014). I congratulate Chico Ferreira on his promotion to the post of Chief Economist, Africa Region, at the World Bank, and thank him for his service to the journal and for his advice to me during the editorial transition period.

To follow in the footsteps of Jacques Silber, Jean-Yves Duclos, and Chico Ferreira is a daunting challenge that I shall do my best to meet. The task is made easier by knowing that the journal's editorial work is a team effort. I am very grateful to the Associate Editors and the Book Review, Forum, and Rediscovered Classics editors for continuing their service.

There are no plans on the immediate horizon for major editorial policy changes. In any case, major changes would be undertaken only after consultation with the Associate Editors, and the Editorial and Advisory Boards. In particular, submitted papers will continue to be handled in the same way. That is, submissions will be initially screened by the Editor-in-Chief and either desk-rejected or allocated to an Associate Editor or myself for further processing. The Associate Editors and I have full editorial discretion over papers allocated to us: we choose reviewers, assess referee reports, and make decisions about acceptance, revision, and rejection. Associate Editors may also desk-reject submissions.

We shall continue to aspire to be fair and to be timely in our quest to publish interesting and innovative contributions to the understanding of economic inequality. More generally, I offer "do unto others as you would have done unto you" as a guiding principle for editors and referees alike.

I look forward to serving as Editor-in-Chief.

Stephen P. Jenkins

S. P. Jenkins $(\bowtie)$

London School of Economics and Political Science, Colchester, UK

e-mail: S.Jenkins@1se.ac.uk 